\title{
A percepção dos sentidos e significados no processo de aprendizagem de Ciências da Natureza nos anos iniciais do Ensino Fundamental
}

\author{
Daniele Muniz de Oliveira* \\ Andrea Anilda Hoffmann da Rocha** \\ Luísa Brum Prestes ${ }^{* * *}$ \\ Victor João da Rocha Maia Santos ${ }^{* * *}$
}

\begin{abstract}
Resumo:
O presente trabalho visa a relatar a análise prévia obtida através da observação da percepção e significados atribuídos pelos alunos durante a realização de atividades experimentais desenvolvidas na oficina de Ciências "Fazendo Arte e Aprendendo Ciências". A oficina foi realizada no laboratório de Ciências do Colégio de Aplicação (CAp) da Universidade Federal do Rio Grande do Sul (UFRGS) com alunos e alunas dos anos iniciais do Ensino Fundamental ( 2 - ao 5 ano). A oficina teve a orientação da professora regente e a participação de duas alunas do Programa Institucional de Iniciação à Docência (PIBID). O objetivo da oficina foi ensinar Ciências da Natureza de forma lúdica com o auxílio da arte buscando motivar o interesse por essa área do conhecimento, e aos poucos, conduzir as crianças, à utilização da linguagem científica. O trabalho realizado com as crianças seguiu as normas de segurança de trabalho em laboratório.
\end{abstract}

\section{Palavras-chave:}

Ciências da Natureza. Sentidos. Significados. Anos iniciais do Ensino Fundamental.

\section{Resumen:}

El presente trabajo tiene por objeto dar cuenta del análisis previo obtenido mediante la observación de la percepción y los significados atribuidos por los alumnos durante las actividades experimentales desarrolladas en el Taller Científico "Haciendo Arte y Aprendiendo Ciencia". El taller se realizó en el Laboratorio de Ciencias do Colégio de Aplicação (CAp) de la Universidade Federal do Rio Grande do Sul (UFRGS) con estudiantes de los primeros años de la escuela primaria (2ํa 5o grado). El taller contó

\footnotetext{
* Graduanda do Curso de Licenciatura em Educação do Campo - Ciências da Natureza da Universidade Federal do Rio Grande do Sul (UFRGS). E-mail: daniele.muniz@hotmail.com. ORCID iD: https://orcid.org/0000-0003-4933-2244.

** Doutora em Química, Pós-Doutoranda em Química (UFRGS). E-mail: deiaahoffmann@gmail.com.

ORCID iD: https://orcid.org/0000-0001-6870-3755.

*** Graduanda do Curso de Licenciatura em Educação do Campo - Ciências da Natureza na Universidade Federal do Rio Grande do Sul (UFRGS). E-mail: luísabrump@gmail.com. ORCID iD: https://orcid.org/0000-0001-7434-3514.

${ }^{* * * *}$ Doutor em Educação em Ciências, professor de Química do CAp da Universidade Federal do Rio Grande do Sul (UFRGS). E-mail: victor.jrms@gmail.com. ORCID iD: https://orcid.org/0000-0003-2274-3756.
} 
con la orientación del maestro regente y la participación de dos estudiantes del Programa Institucional de Iniciación a la Enseñanza (PIBID). El objetivo del taller era enseñar las Ciencias de la Naturaleza de forma lúdica con la ayuda del arte, buscando motivar el interés por esta área del conocimiento, y poco a poco, guiar a los niños en el uso del lenguaje científico. El trabajo realizado con los niños siguió las normas de seguridad del trabajo de laboratorio.

\section{Palabras-clave:}

Ciencias de la Naturaleza. Sentidos. Significados. Primeros años de la escuela primaria.

\section{Introdução}

O presente trabalho tem como finalidade apresentar os resultados preliminares adquiridos por meio da realização de atividades experimentais desenvolvidas na oficina de Ciências "Fazendo Arte e Aprendendo Ciências". A prática da oficina foi realizada no laboratório de Ciências do Colégio de Aplicação (CAp) da Universidade Federal do Rio Grande do Sul (UFRGS). A oficina foi oferecida como disciplina eletiva e teve a participação de alunos e alunas dos anos inicias do Ensino Fundamental do CAp-UFRGS na modalidade multisseriada com estudantes do $2^{\circ}$ ao $5^{\circ}$ ano matriculados.

A orientação da oficina foi realizada pela professora regente com a cooperação de duas alunas do Programa Institucional de Iniciação à Docência (PIBID). O objetivo da oficina foi de ensinar Ciências da Natureza de maneira lúdica com a contribuição da arte, almejando motivar o interesse por essa área do conhecimento e conduzir as crianças para a utilização da linguagem científica de forma gradual.

As aulas no laboratório seguiram os protocolos de segurança, e foi ensinado para as crianças, algumas normas, tais como: não cheirar (olfato) e não colocar na boca (paladar) os experimentos. Efetuar as tarefas com cuidado no manuseio dos materiais do laboratório e nas práticas.

A metodologia utilizada para a coleta das informações foi através dos desenhos produzidos pelos alunos e alunas ao final de cada aula, a participação através da fala nas atividades antes do experimento ter início, durante e até sua conclusão. Os estudantes usaram também materiais como folha de ofício "A4", canetas e lápis coloridos assim como outros itens de seus pertences para desenho.

As atividades foram testadas e executadas no laboratório de Ciências do Colégio de Aplicação e ao longo das aulas as crianças apresentaram interesse em aprender, como também, em demonstrar e compartilhar suas atividades com familiares, professores e colegas na Mostra, um dia reservado para a exposição de todas as oficinas ofertadas no primeiro semestre. Por fim, teremos a análise prévia dos resultados obtidos ao longo das atividades executadas na oficina no primeiro semestre do ano de 2019.

\section{Metodologia}

A observação a partir da percepção que os alunos e alunas demonstraram durante os experimentos, a coleta dos registros através de desenhos e da escrita livre, a participação espontânea através da fala, do tato, da audição e a visão dos estudantes foram as principais ferramentas utilizadas para a coleta dos dados.

A metodologia utilizada para a coleta dos dados foi de observação participante. Os dados foram registrados através da observação, registro das atividades ao final da aula com os desenhos e escrita livre executados pelos alunos, fotos e vídeos e anotações em um caderno semanalmente conforme o horário estabelecido pelo CAp-UFRGS para a realização da oficina.

Algumas medidas de segurança foram adotadas para evitar acidentes ou qualquer dano para as crianças. Limitamos alguns sentidos como não cheirar (olfato) não colocar na boca (paladar) durante as atividades propostas. O uso do tato foi permitido em experimentos que essa função era primordial para a realização da tarefa. 
A execução das atividades foi determinante para o registro dos dados coletados. Os materiais, pertencentes ao laboratório de Ciências do Colégio de Aplicação (CAp-UFRGS), foram apresentados no início das atividades. Os itens escolares utilizados para os registros dos alunos e alunas após os trabalhos foram folhas de ofício "A4" de gramatura simples, lápis grafite, assim como lápis e canetas coloridas e borrachas.

Ao permitir que os estudantes selecionassem as cores para a realização das atividades, colocamos em prática, diversas maneiras que possibilitaram a execução das tarefas de forma criativa.

\section{A oficina}

O trabalho na oficina "Fazendo Arte e Aprendendo Ciências" foi realizado no laboratório de Ciências do Colégio de Aplicação (CAp) da Universidade Federal do Rio Grande do Sul (UFRGS). O local é usado para aulas práticas para os estudantes do Ensino Fundamental e Médio. O lugar é amplo e conta com uma estrutura bem conservada e organizada. Os materiais ficam alojados em uma sala com o formato de "dispensa" que é fechada e somente os professores e professoras têm acesso aos materiais contidos nela.

As mesas redondas e menores para os trabalhos em grupos ficam posicionados ao redor de uma mesa maior localizada no centro da sala onde realizamos os diálogos iniciais e a explicação prévia da atividade. No laboratório, existe uma pequena exposição de algumas espécies de animais conservados, o que chamou a atenção dos estudantes logo no primeiro dia em que conheceram o laboratório. Em uma parede existe o desenho de uma árvore com várias espécies de animais que também foi muito observada pelo grupo.

A oficina foi ofertada para os estudantes dos anos iniciais do Ensino Fundamental e as atividades iniciavam após os intervalos das aulas regulares uma vez por semana, nas terças-feiras nos dois últimos períodos.

O objetivo da oficina foi de ensinar Ciências de forma lúdica, criativa com a participação dos estudantes e aos poucos introduzir a linguagem científica para os alunos e alunas. Um diálogo inicial com as crianças possibilitou um mapeamento das atividades que o gostariam de realizar na oficina. Uma pequena rotina foi estabelecida, com a conversa inicial em grupo antes das atividades, o que reforçou o estabelecimento de um vínculo afetivo como também despertou o interesse dos estudantes no aprendizado.

Os experimentos eram testados com antecedência. Algumas aulas foram reservadas para a prática das atividades que os alunos escolheram, como por exemplo, um "vulcão", como aqueles que apareciam nos filmes e nas feiras de Ciências e o "slime", uma massa colorida com a textura de um "chiclete" ou a famosa goma de mascar e a atividade "sangue de unicórnio tipo A e tipo B", mistura de suco de limão e laranja e dois tipos de "glitter" (um pó solúvel e o outro material em partículas) foi baseada em um filme do gosto das crianças.

Algumas combinações foram a acordadas para a realização das atividades como: não colocar nada na boca e não cheirar os ingredientes dos experimentos. Essas combinações foram feitas, pensando na segurança dos estudantes. Em alguns casos, em que a atividade necessitava do tato e de alguns sentidos que foram limitados, foi permitido usar os sentidos limitados, desde que orientados pela professora regente e as bolsistas "pibidianas". Porém, na maioria das atividades que utilizavam ingredientes foi reforçado as condições para segurança.

Com essas limitações, os sentidos foram trabalhados de forma a exercitar a fala, a audição e a representação das atividades ficaram por conta do momento de registro nos desenhos e na escrita realizados no final de cada aula.

A prática de uma conversa antes das atividades permitiu o aprendizado do conteúdo de Ciências de uma forma leve e descontraída podemos reforçar que um dos fatores que observamos na realização da oficina foi que permitir esse espaço contribuiu para estudar Ciências adicionando os conteúdos importantes com atividades lúdicas transformou o aprendizado para os alunos e alunas mais articulado e prazeroso.

Podemos também ressaltar a importância de a oficina ser eletiva, assim é uma escolha do aluno, dessa forma damos a oportunidade de aprender Ciências de um outro jeito, mais participativo e agradável. 
A união do sentido de responsabilidade e compreensão por quem organiza e para quem aprende tem um peso marcante na acepção do crescimento pessoal e intelectual para todos os envolvidos.

\section{A Mostra}

O dia mais esperado para os alunos e alunas que participaram da oficina "Fazendo Arte e Aprendendo Ciências" é a Mostra. Ele é reservado para a apresentação das atividades escolhidas pelos estudantes, com a finalidade de socializar com familiares, professores de outras oficinas e turmas e colegas. O momento em que as crianças compartilham os conhecimentos adquiridos e mostram os experimentos.

A Mostra foi realizada no último dia da oficina e os alunos escolheram previamente quais os experimentos seriam apresentados. A turma foi dividida em dois grupos, com cinco alunos, para que todos pudessem visitar as outras oficinas que também estavam acontecendo simultaneamente. Enquanto o primeiro grupo apresentou os experimentos o segundo visitava as outras oficinas e após, passado o tempo determinado, os grupos trocavam.

A organização do espaço reservado para a Mostra foi executada por todos os alunos, professora regente, professor supervisor e as alunas bolsistas do programa "PIBID". A mesa onde os experimentos foram realizados estava organizada em "L" para melhor expor as atividades e os desenhos realizados pelos estudantes foram expostos em um varal.

Todos tiveram a oportunidade de apresentar os experimentos escolhidos para seus pais, mães, avós, professores, professoras e colegas. A alegria estava estampada em seus rostos muito mais que a preocupação e o nervosismo. Esse foi o dia mais aguardado e movimentado dos alunos e alunas. As crianças tiveram a oportunidade de demonstrar os experimentos e socializar os conhecimentos de Ciências adquiridos nas aulas realizadas na oficina.

Além de demonstrar em tempo real alguns experimentos, nesse dia observamos o crescimento pessoal e intelectual das crianças através de suas falas e posturas na hora de apresentar e explicar cada experimento. A Mostra, que tanto foi esperada por todos, atingiu seus objetivos, possibilitando socializar e compartilhar os conhecimentos que foram realizados durante a oficina.

\section{Referencial teórico}

O trabalho realizado com os alunos e alunas dos anos iniciais do Ensino Fundamental proporciona uma visão específica na construção da percepção dos conhecimentos e como as crianças percebem qual assunto é importante e os aleatórios, mas com atributos cheios de significados.

Conforme Fontana (2005) quando nossa realidade é confrontada, os saberes que temos sofrem uma mudança bem significativa. A prática da sala aula nos transforma e amplia nossa visão de mundo e percebemos a origem do desejo pela prática docente. E no momento que podemos observar que nossa ação está atuando de forma direta na maneira como os estudantes percebem o mundo e nossa identidade como professores e professoras estamos prestes a emergir e fortalecer o vínculo entre aluno e professor.

A realidade de quem ensina está sempre em constante movimento com "provações" diárias em que muitos casos não segue um padrão e não há como evitar que os objetivos sejam alcançados da forma que os docentes gostariam. Assim, precisam buscar muito mais do que encontram nos livros, e com isso, fazer a mudança quando a existência real se faz forte como nunca.

Aprendemos muito com a observação dentro de uma sala de aula. Mas é com a prática que concretizamos o que estudamos nas teorias. Conseguimos adquirir somente pela prática desde as leituras, planejamentos e testes para a aplicação dos conteúdos para os alunos e alunas.

Para Freire (1965), a liberdade de ensinar está em conservar a história de vida de cada aluno. A modalidade regular dos anos iniciais do Ensino Fundamental traz a concepção de que podemos inserir de 
forma gradual além do conteúdo programado, novas experiências, contribuindo na apropriação dos conhecimentos. Os atributos em que o conhecimento aprendido na sala de aula comparado com os momentos vivenciados pelos alunos e alunas só reforça que a maneira como é introduzido os fundamentos faz toda a diferença na vida dos estudantes e que além de benefícios educacionais fortes é capaz de produzir um efeito marcante e por fim mais que duradouro na vida deles.

Segundo Lima (2013) a maneira como a criança interage na aula está de modo que ultrapassa a fala. A interação acontece também nos gestos e expressões faciais. A compreensão do universo em que as crianças são dominantes em seus grupos de afinidades passa fortemente o "muro" das relações e no momento em que o princípio ativo é a participação, elas são fluentes no vocabulário oral, corporal e suas expressões faciais são correlatas com suas dúvidas, seus questionamentos e também com a compreensão dos conteúdos e o que acontece ao seu redor.

O trabalho desenvolvido em pares ou em grupos nos permite um olhar mais dinâmico nas diversas maneiras em que as crianças se relacionam entre si e com os demais. Aqueles em que a participação não é tão efetiva e os que participam de forma pontual nas atividades demonstram um igual interesse, porém existe a possibilidade de algumas reações passarem despercebidas já que os grupos podem ser formados pelos mesmos indivíduos.

Por isso, existiu uma tentativa de diversificar os grupos de trabalho o que permitiria uma maior interação e aceitação do outro.

Em nossas ações pedagógicas, tenhamos um olhar sensível para percebemos o que as crianças sempre estão a nos mostrar em suas relações. Assim estaremos trabalhando as diferenças nas formas de organização social, o respeito à diversidade, as manifestações culturais e normas de funionamento grupal e social, a ética da solidariedade e a tolerâcia. (LIMA, 2013, p. 77).

A participação dos estudantes nas atividades não deve ser utilizada com margem para reforçar os conceitos aplicados e sim com uma forma de aprendizado em que questões são discutidas pelo grupo e as práticas executadas de maneira agradável e fluida.

Portanto, ao reforçarmos que ao permitir que os alunos se sintam à vontade para participar das aulas, atuando, questionando, segundo Lima, fortalecemos vários princípios que auxiliam no desenvolvimento de indivíduos ativos e críticos (LIMA, 2013).

A luta contra um tempo em que uma prática libertadora de ensinar não está em valor efetivo e embora, seja uma dura caminhada para alcançar os objetivos propostos em sala, se faz em uma crescente presença fortalecendo aos poucos, nessa faixa, a evolução nos pensamentos e é nessa idade que nossos alunos e alunas caminham lado a lado com tudo o que tem algum significado para eles (FREIRE, 1965).

A Ciências e a arte são disciplinas muito importantes para o aprendizado. Uma domina a razão e a lógica a outra incentiva a percepção e a emoção. A colocação de ambas dentro do mesmo espaço fortalece a forma como o conhecimento é adquirido pelos alunos e alunas. Para Silva e Fraga (2017), a união das duas disciplinas realça uma visão singular com o mesmo enfoque, o conhecimento.

\section{Resultados e discussão}

Os resultados obtidos com as atividades realizadas na oficina demonstram até o presente momento uma interação singular com o aprendizado e a diferenciação dos sentidos e dos significados em como as crianças interpretam as ações realizadas durante as atividades na oficina de Ciências. A conversa inicial antes de cada aula abriu espaço para que os alunos participassem do começo ao final de cada atividade realizada.

A coleta das informações começou a partir da observação de como cada criança interagia com a atividade, com os desenhos e a escrita de forma livre realizados no período destinado no fim de cada aula. 
A forma como cada criança compreendia a maneira de associar as palavras aprendidas em seus desenhos, as cores que se misturavam e ao tocar nos experimentos que na atividade era permitido o uso do tato.

O aprendizado começou no primeiro dia de oficina, e o diálogo inicial foi muito importante para a elaboração das aulas seguintes. As crianças relataram seus desejos em relação as atividades, preferências de filmes e outras formas de entretenimentos (livros, histórias em quadrinhos, seriados e desenhos animados) e quais eram suas expectativas dos experimentos que seriam realizados na oficina. Os assuntos que dialogaram sobre seus desejos serviu para uma análise de seus conhecimentos prévios e após as atividades iniciadas as novas palavras que foram aprendendo ao longo da oficina como por exemplo "polar e apolar", "sintéticos e artificial" relacionadas com a linguagem científica foram introduzidas na rotina dos alunos, porém, o mais relevante foi que na limitação de dois sentidos principais, assim os alunos e alunas buscaram perceber as atividades através do diálogo com a professora regente e as duas alunas bolsistas.

A fala, a audição, o tato e a visão foram provocados de forma construtiva. $\mathrm{O}$ trabalho foi fortalecido com a demonstração da curiosidade das crianças e como elas se expressaram na realização das atividades. Essa curiosidade colaborou na percepção dos sentidos como uma base inicial do processo para a análise dos dados. A utilização do tato quando a atividade precisava dessa função, a fala e audição, assim como o uso dos sentidos na personificação dos significados para as palavras, sons, texturas e os objetos.

A construção de atividades informais e com atrativos diferenciados estimulou os sentidos que não se encontravam limitados e a demonstração dos significados que foram atribuídos mostraram-se importantes para a coleta dos dados. Um laço foi estabelecido desde o primeiro dia de aula, quando foi aberto para os alunos e alunas o espaço da fala de como foi o final de semana de cada um, quais foram suas atividades e percebemos que algumas crianças já buscavam informações sobre outras atividades que gostariam de realizar na oficina.

\section{Sentidos e os significados na aprendizagem}

A percepção dos sentidos está nos objetivos do que era ensinado e o como eles usavam em suas rotinas diárias. A escolha de alguns dos elementos como as cores dos corantes utilizados nos experimentos deixou claro que as crianças percebem o mundo a sua volta de várias maneiras e com isso conseguem uma dinâmica maior com a realidade vivenciada.

A colocação de limitações nos sentidos físicos como o olfato, paladar e o tato não impediu de forma alguma a construção do conhecimento atrás da fala, da visão e audição, pelo contrário, as limitações impostas permitiram que os alunos e alunas demonstraram que poderiam apresentar os resultados ao final do dia de forma criativa e muitas vezes rápidas e práticas.

A fala aqui representa um "sentido físico extra" e conecta com os significados em que foram atribuídos ao longo das atividades desenvolvidas na oficina. Os questionamentos que surgiram no decorrer dos experimentos foram uma maneira de analisar como os sentidos estão ligados aos significados das palavras novas que foram agregadas ao vocabulário das crianças, saber como e por qual motivo estamos usando a palavra "sintético" e qual a finalidade do termo e que podemos usar a palavra "artificial" como sinônimo, são significados que as crianças aprenderam quando realizamos uma atividade com "sangue de unicórnio" e abrir uma porta para novos usos para esses vocábulos. O motivo pelo qual os sentidos foram importantes nesse aprendizado está na atribuição dos significados que ocorre tanto nas palavras cientificas que as crianças aprenderam como a sua utilização na rotina e não apenas na escolar, na cotidiana. $\mathrm{O}$ estudo de Ciências da natureza foi incentivado nesse processo criativo ao permitir a escolha das cores nas atividades e executando atividades propostas pelos alunos e gradualmente inserindo novas palavras e significados científicos para os alunos e alunas. 


\section{A arte como conexão no aprendizado de Ciências da Natureza}

O estudo da Ciências da Natureza carrega a "imagem” forte de que precisamos aprender as inúmeras matérias. A oficina proporcionou aos alunos e alunas uma maneira divertida de aprender Ciências. A participação dos estudantes desde o primeiro dia da disciplina trabalhou de forma em que a arte esteve presente de modo significativo.

A livre participação através do diálogo das expectativas do que os alunos iriam aprender até a colocação de seus gostos por filmes, desenhos animados, livros, seriados foi uma maneira de expressão muito importante. E no decorrer das atividades propostas a ação dos alunos e alunas no lugar da escolha dos professores sobre qual cor seria usada no experimento ou qual grupo seria formado e seus membros escolhidos para o desenvolvimento das atividades revelou a disposição das crianças para aprender ciências.

O aprendizado de Ciências de forma lúdica sem ter uma obrigação dos alunos e alunas preencherem os cadernos deixou a "atmosfera” da aula mais descontraída. No lugar de uma ordem específica do professor surgiu um posicionamento cheio de atitude dos estudantes.

Ao contrário do que podemos imaginar o fato de não ter um registro totalmente convencional das aulas não interferiu na proposta de aprendizagem da linguagem científica muito menos na qualidade do ensino adquirido. O estudo da Ciências da Natureza vinculado ao esboço artístico no final da manhã de cada aula resultou em trabalhos expressivos e com nexos da iniciação da linguagem científica.

A arte expressa nos desenhos não são apenas criativos, eles demostraram como cada criança percebe o que aconteceu durante a aula e como sua percepção de vida se encaixo no conteúdo aprendido. Ela serviu como um elo entre o aprendizado de Ciências da Natureza de uma forma lúdica. A possibilidade de criar e interagir de forma livre ao registrar o conteúdo aprendido demonstra como a ciências e a arte se uniram. A ligação criada entre o conhecimento e a prática do experimento está diretamente vinculado na forma como as crianças se relacionam com o aprendizado de Ciências na proposta da oficina que foi de introduzir a linguagem cientifica de forma gradual com o auxílio da arte utilizada como uma ferramenta importante de expressão da percepção do aprendizado na vida dos alunos.

\section{Considerações finais}

A limitação de dois dos principais sentidos, como o olfato e o paladar resultaram na ampliação dos demais como a audição, a visão, o tato e principalmente a fala. Eles foram essenciais para a conclusão de várias atividades nas aulas da oficina de Ciências. As novas sensações expressas em sua grande parte pela fala demonstram ao final da disciplina um crescimento tanto no vocabulário como na percepção do conhecimento que os alunos e alunas adquiriram.

As crianças demonstraram um conhecimento prévio de alguns termos significativos e ao longo das aulas atribuíram os sentidos nas palavras e os significados dos motivos pelo qual estavam estudando um determinado assunto e por mais complexo o conteúdo, uma nova visão foi fixada ao longo do desfecho das atividades.

O trabalho realizado na oficina de Ciências foi muito importante e podemos observar com a análise dos dados prévios obtidos através dos diálogos antes das atividades começarem, dos desenhos e com a escrita livre um crescimento de forma gradual tanto no processamento das informações como na sua aplicação diária. As crianças demonstraram interesse nas aulas desde o primeiro momento em que foi aberto um espaço para o conhecimento de suas vontades e desejos no que gostariam de aprender na oficina e manifestaram um reconhecimento do aprendizado obtido na apresentação dos experimentos na Mostra, evento em que os alunos e alunos escolheram com experiências seriam apresentadas para familiares, convidados, professores e colegas.

Podemos observar na apresentação da Mostra um crescimento pessoal e intelectual dos alunos. A maneira como os experimentos foram escolhidos pelas próprias crianças firmaram, de uma certa maneira, segurança em suas apresentações para familiares, docentes e colegas. A percepção da postura dos alunos 
e alunas, que no começo da oficina eram mais reservados, transformada numa postura segura de si e seus conhecimentos para a apresentação foi gratificante e possibilitou a apresentação de todo seu crescimento perante a finalização da oficina.

O momento em que podemos observar que as crianças conseguiram atribuir sentido e um significado em tudo que estava a sua volta e como isso foi importante para eles foi de grande satisfação. A fala para alguns alunos e alunas na hora da apresentação foi de suma importância e uma comoção foi observada em seus familiares ao perceberem suas posturas no momento da explicação. A limitação não trouxe algum tipo de empecilho, pelo contrário, permitiu que as crianças trabalhassem mais sua percepção de mundo cotidiano e de sala de aula. Expressões e palavras de sentido científico foram adicionadas no vocabulário das crianças e mesmo limitando alguns sentidos não impediu que suas atividades fossem realizadas e os objetivo propostos alcançados ao decorrer do acontecimento da oficina.

Portanto, com base nos resultados analisados até o presente momento podemos dizer que os sentidos limitados nas atividades aproximaram os alunos e alunas de forma que exercitavam a fala nos questionamentos, o tato, quando o experimento permitiu, e transportando para uma visão do senso de significação. As novas palavras da linguagem científica que as crianças foram adquirindo ao longo das atividades exercidas na oficina contribuíram de maneira relevante para aprendizado.

\section{Referências}

FONTANA Roseli A. Cação. Como nos tornamos professoras? 3. ed. Belo Horizonte: Autêntica, 2005.

FREIRE, Paulo. A educação como prática da liberdade. Rio de Janeiro: Ed. Paz e Terra LTDA, 1965.

LIMA, Patrícia de Moraes. Didática e Planejamento. Curitiba: Ed. FAEL, 2013.

SILVA, Andréia Santos; FRAGA, Nayhara Marylin. A Arte aplicada ao ensino de Biologia: confecção de modelos didáticos de microrganismos. Revista Educação Pública, Rio de Janeiro, v. 17, n. 11, 30 maio 2017. Disponível em: http://educacaopublica.cecierj.edu.br/revista/?p=41368. Acesso em: 18 jul. 2020.

Data de submissão: 19/06/2020

Data de aceite: $25 / 07 / 2020$ 